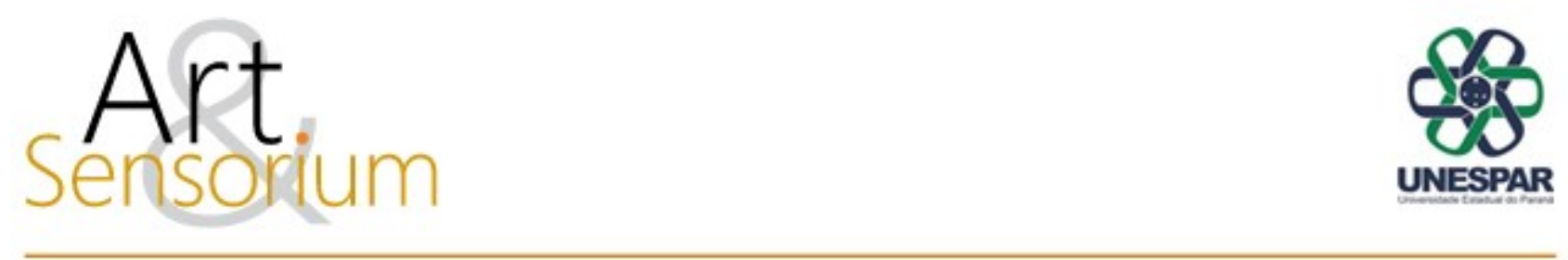

\title{
NÃO É BIGBANG, É O BIGBOOM DA LIVE!
}

\author{
DOI: https://doi.org/10.33871/23580437.2020.7.2.181-192
}

Meriney dos Santos Hortal

Fernanda de Oliveira Nicolini ${ }^{2}$

\begin{abstract}
RESUMO: Em meio à pandemia de Covid-19, os espaços físicos de circulação dos corpos foram transvertidos em uma maior circulação pelo meio virtual. Corpos antes vistos em materialidade passam para uma imagem que se mostra restrita ao enquadramento da tela. Nesse contexto, emergem as mais diversas lives e com elas surge toda uma gama de códigos estabelecidos como normais ao uso dessa plataforma. Tocadas por essas e outras questões, as autoras desse texto desenvolveram a "Performance em Pauta", uma contra-performance que se mimetiza de live e abre conexões outras de presença, afeto e da própria pesquisa artística de ambas as proponentes. Em duas edições realizadas da ação, a coautoria se torna uma constante, tanto pela atuação do próprio dispositivo digital/rede de internet que dialoga com as performers por meio da oferta de falhas e erros recorrentes e prontamente incorporados ao trabalho, quanto pela coautoria dos espectadores que assistiam ao trabalho e passam a interferir deliberadamente na construção de outras imagens a partir do que recepcionam. Neste artigo, analisamos a criação e desenvolvimento deste trabalho no contexto do isolamento social que atravessa nossas pesquisas, da mesma forma que damos atenção às questões que o próprio fazer da "Performance em Pauta" suscita nas pesquisadoras e no público.
\end{abstract}

PALAVRAS-CHAVE: performance; mídias digitais; tecnologia; arte contemporânea; pandemia.

\section{IT'S NOT A BIGBANG, IT'S A LIVE'S BIGBOOM!}

\begin{abstract}
In the midst of the Covid-19 pandemic, the physical spaces for the circulation of bodies were transformed into a greater circulation through the virtual environment, the bodies, previously seen in materiality, pass to an image that is restricted to the framing of the canvas. In this context, the most diverse lives emerge and with them comes a whole range of codes established as normal to
\end{abstract}

\footnotetext{
${ }^{1}$ Mery Horta é artista e pesquisadora das áreas relacionadas de artes visuais, performance e dança. Doutoranda e Mestre em Artes Visuais pelo PPGAV EBA UFRJ. Graduada no Bacharelado em Dança da UFRJ. Integrante do Mó Coletivo e do grupo Ateliê Terreiro. Desenvolve trabalhos interdisciplinares com o uso de diferentes linguagens e dispositivos, considerando a relação entre corpo-objeto a partir de memórias-invenções apresentando seus trabalhos em diversas exposições e eventos. Site: www.meryhorta.wixsite.com/arte PPGAV EBA UFRJ, Rio de Janeiro, RJ, Brasil, meryhorta87@gmail.com ORCID: 0000000205373995

${ }^{2}$ Fernanda Nicolini é bailarina, performer e pesquisadora. Mestranda em Dança pelo PPGDan UFRJ, é graduada em Design e especialista em ucycling. Investiga desde 2015 as relações entre corpos e objetos, materiais e imateriais e o conceito de corpo formado a partir desta relação. É criadora do video Message to Balzac (2020) selecionado pelo TanzTheaterWuppertal Pina Bausch Create(AL) durante o isolamento social e também das performances Manual Derivado (2018) e O.T.R.A.(2019). Site: www.fenicolini.wixsite.com/fernandanicolini. PPGDan UFRJ, Rio de Janeiro, RJ , Brasil, ferdinicolini@gmail.com ORCID: 00000002 9644-3783
} 
the use of this platform. Touched by these and other issues, the authors of this text developed "Performance em Pauta", a counter-performance that mimics live and opens other connections of presence, affection and the artistic research of both proponents. In two editions of the action, coauthorship becomes a constant: both by the performance of the digital device / internet network that dialogues with the artists through the offer of recurring flaws and errors and readily incorporated into the work, as well as by the co-authorship of the audience. who watched the work and started to deliberately interfere in the construction of other images from what they receive. In this article we analyze the creation process of this work in the context of social isolation that crosses our research, in the same way that we pay attention to the questions that the "Performance em Pauta" itself raises in the researchers and the public.

Keywords: performance; digital media; technology; contemporary art; pandemy.

\section{¡NO ES BIGBANG, ES LO BIGBOOM DE LIVES!}

RESUMEN: En medio de la pandemia Covid-19, los espacios físicos para la circulación de los cuerpos se transformaron en una mayor circulación a través del entorno virtual, los cuerpos previamente vistos en materialidad pasan a una imagen que se restringe al encuadre del lienzo. En este contexto, surgen las lives más diversas y con ellas todo un abanico de códigos establecidos como normales para el uso de esta plataforma. Tocados por estos y otros temas, los autores de este texto desarrollaron "Performance em Pauta": una contra-performance que imita en vivo y abre otras conexiones de presencia, afecto y la búsqueda artística de ambos proponentes. En dos ediciones de la acción, la coautoría se convierte en una constante: tanto por la actuación del dispositivo digital / red de internet que dialoga con los intérpretes a través de la oferta de fallas y errores recurrentes y fácilmente incorporados a la obra; como por la coautoría de los espectadores viendo la obra y comenzaron a interferir deliberadamente en la construcción de otras imágenes a partir de lo que reciben. En este artículo analizamos la creación y desarrollo de este trabajo en el contexto de aislamiento social que atraviesa nuestra investigación, de la misma manera que prestamos atención a las preguntas que el propio "Performance em Pauta" plantea en los investigadores y el público.

PALABRAS CLAVE: performance; medios digitales; tecnología; arte contemporaneo; pandemia.

Em março de 2020 nos deparamos no Brasil com uma nova realidade desoladora que já havia sido instituída poucos meses antes em outros países do mundo. A pandemia de Covid-19 instaurou o corpo humano como potencial vetor da doença, e, assim, limitou nossos lugares físicos de circulação, restringindo-os, na maioria dos casos, ao nosso próprio mundo-casa. Com a vida se reestruturando nesse espaço abreviado de cômodos e objetos caseiros, o uso da internet e dos dispositivos digitais se intensificou a níveis astronômicos e passou a ser o meio praticamente predominante da comunicação, da aprendizagem, do trabalho, do lazer, do afeto. $\mathrm{O}$ isolamento social poderia ser chamado de isolamento físico, pois parte das relações sociais continuaram existindo mesmo à distância, mas o convívio social, aquele que depende do contato físico de dois ou mais corpos para existir, foi interrompido de forma brusca pela necessidade.

$\mathrm{O}$ acesso ao mundo pela via virtual expôs a carência da presença do outro e evidenciou alguns fenômenos que aconteceram nesse cenário como o boom das lives. A live foi criada como uma ferramenta do aplicativo Instagram que desse um caráter ainda mais rápido, mais fetichizado em relação à presença do corpo. Como um recorte da vida transmitida ao vivo, em tempo real com seus segredos e, também, como um meio para monetizar estes mesmos segredos. O enquadramento da tela sempre deixa escapar um canto, uma intimidade da casa, um produto, um bem de consumo. Uma enxurrada de transmissões ao vivo pipocou com os mais diversos conteúdos e temáticas nas 
diferentes plataformas, que passaram a disponibilizar também esta ferramenta, como Facebook e Youtube para citar alguns. Em uma grande contradição, boa parte das pessoas não se via desfrutando do tempo ocioso, agora que essa possibilidade advinha do trabalho em casa, para quem pode mantê-lo, sem precisar se expor ao risco do contágio. O próprio tempo do decorrer das coisas parecia outro, um tempo talvez alterado pelas mudanças dos espaços de trânsito do corpo, das demandas caseiras e do estrondoso clima fúnebre que recobriu inevitavelmente o mundo inteiro. $\mathrm{O}$ tempo da folga precisava ser ocupado, preenchido com assuntos dos mais diversos. As pessoas precisavam falar, compartilhar seus conteúdos, fazer algo com o suposto tempo 'livre'. Precisávamos seguir atendendo à mobilidade produtiva do capital mantendo nossos empregos ou tornando-nos empreendedores de nós mesmos, girando a roda da mais-valia. Ou apenas precisávamos nos sentir menos só.

Nesse contexto, que em muitos momentos nos lembra um filme apocalíptico sem a parte da encenação, muitos artistas se viram na função de readaptar suas formas de trabalho, pesquisa e produção, já que o museu e o teatro são lugares de aglomeração, assim como a rua, a sala de aula e a galeria. A arte parte do pressuposto de (re)unir pessoas, presencial ou virtualmente. A fruição de um trabalho se dá a partir do momento que ele é visto, sentido, apreendido pelo outro. Portanto, se a presença não é possível fissicamente, a rota de fuga se dá através dos ambientes digitais. Nesse risco vital do corpo na circulação por outros locais fora do mundo-casa, o ciberespaço se mostra como o lugar viável para a divulgação dos trabalhos artísticos, exposição, apreciação e, porque não, criação. A tela e o monitor se abrem como uma das janelas da casa, ante a propriedade de possibilitar o acesso para uma dimensão do mundo imaterial (DOMINGUES, 1997).

Esta dinâmica de experimentação e criação em arte e tecnologia digital/virtual não consiste em novidade ou mesmo ineditismo, visto que as pessoas ao redor do mundo trabalham nesse sentido desde meados do século XX, estabelecendo uma gama imensa de pesquisas e obras que permeiam o tema. Considerando esse cenário aterrorizante de pandemia, não há invenções ou descobertas geniais a tratar aqui. Todavia, nos dispomos a observar e deixar vir à tona o que já existe dentro desse "novo" cenário e suas brechas para a criação artística. As relações humanas precisam existir, se não materialmente que seja por live, videochamada, videoaula, áudios no whatsapp ou, ironicamente, por ligações telefônicas. Tudo o que for válido para que os corpos continuem vendo, sentindo e se relacionando, mesmo que virtualmente. Aqui, nós, as artistas, não somos seres que pairam acima da existência de sentimentos cruzados por boa parte da humanidade ao viver esse período. Nossos corpos também se reorganizam a cada notícia de morte. Experimentar, criar arte é como respirar, comer, dormir, como necessidade vital para tentar, ao menos, lidar com esse tempo, pensando nosso tempo com arte, com reflexão, reafirmando o campo neste espaço de ataques às subjetividades e às diversas formas de pensamento.

Importante frisar neste ponto que falamos de afeto, de compartilhamento entre corpos, de troca de energia, mesmo que esta precise passar pela corrente elétrica através de um modem de internet, ou circular "em satélites que conversam no céu" (DOMINGUES, 1997, 18) para que se instaure relações entre pessoas. Temos claro em nossos processos e propostas que a exclusão digital também se mostra como uma questão que foi apenas ressaltada pela necessidade de uso atual, mas que sempre existiu assim como os recursos para implantação ampla do direto de acesso de todos à internet, como bem público, mas não executado até aqui. No Brasil tal questão não se mostra como uma inviabilidade por falta de recursos, mas sim por parte integrante do projeto de banir o acesso à informação para uma grande parte da população. Estas são questões que nos atravessam a todo instante, mas acreditamos que condenar o uso da tecnologia nesse momento, pode ser um lugar privilegiado. Para que uma crítica se formalize nesse sentido seria possivelmente necessário o uso da tecnologia virtual para chegar às pessoas, o que por si só já seria uma alarmante contradição. Ao mesmo tempo não inclinamos o pensamento no sentido de um culto ao uso dos dispositivos e aparelhos tecnológicos, mas que estes possam ser incorporados crítica e conscientemente na utilidade e subjetividade da vida em meio à pandemia. 


\section{Oralidades do corpo}

No constante cronograma de "ao vivo" que surge a cada dia do isolamento, as pessoas falam sobre os mais diversos conteúdos, as pessoas falam. Corpos se posicionam diante da câmera do celular ou computador e o que vemos são telas, geralmente divididas, onde aparecem duas ou mais pessoas sentadas com uma luz que ilumina bem seus corpos segmentados pelo enquadramento. Onde se evidenciam as pupilas desenhadas pelos ringlights, os anéis de luz famosos entre os youtubers e agora entre nós, reles mortais, olhando na direção do dispositivo e falando para manter a credibilidade, como os coaches de conteúdo gostam de aconselhar. Essa breve descrição traz algumas convenções que parecem ter sido pré-estabelecidas como em um acordo tácito de como deveria ser a formalidade que inclui o modo do corpo estar diante desses dispositivos. Como se portar? Como deve ser essa imagem do corpo diante da tela? E se o corpo assumisse um movimento de desvio nessa profusão de oralidade? Uma conversa sem palavras, olhares que contam histórias, pequenos gestos que dialogam. Uma proposta em que os corpos se afirmem nessa outra conversa, assumindo que o espaço não se restringe às duas dimensões da tela, mas se expande. Ao se colocarem em outras situações, movimentando e procurando formas outras de estarem em diálogo entre si e com a visualidade pela qual são transmitidas as suas imagens.

Como uma provocação a estas e outras questões, nasce a ação intitulada "Performance em Pauta" realizada em duas edições durante os meses de julho e agosto de 2020, unindo nós, autoras desta escrita. Aliás, sobre nós autoras, é importante dizer que também temos nossa amizade e encontro profissional unicamente a partir da virtualidade. Não nos conhecemos fisicamente e esta é mais uma relevante característica que dá força à performatividade de nossa pesquisa conjunta pela compreensão deste não-lugar-todo-lugar do online, destes corpos pulverizados em muitos corpos a partir do mesmo, em corpos multicanais.

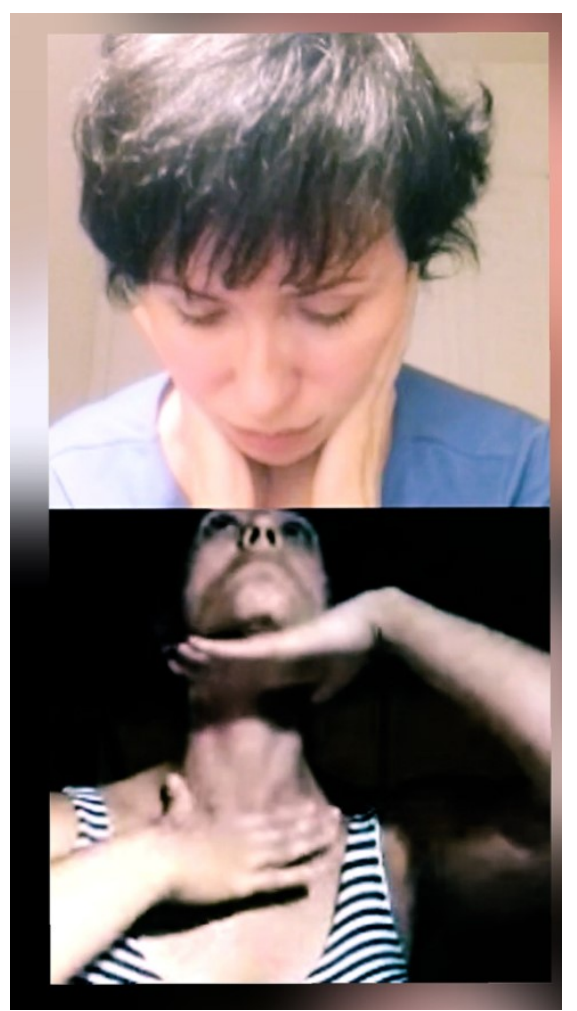

Figura 1: Performance em Pauta - Ação 1 
Nossos ips $^{3}$ se cruzaram após uma reunião para uma determinada atividade relacionada a outro projeto de investigação performática online. De modo despretensioso, partilhando desabafos sobre a situação, revelamos inquietações convergentes e curiosidades que mais tarde se fizeram como uma espécie de metodologia de processo de criação para as ações. Na "Performance em Pauta", realizada para pensar comportamentos e o espaço delimitado para lives no aplicativo Instagram, nossos corpos conversam por gestos em dia e hora agendados, tendo nossa metodologia da curiosidade e do estranhamento como norte. Elencamos, anteriormente a cada ação, perguntas como nossas pequenas regras, mesmo sabendo que tudo poderia mudar a qualquer instante. Às vezes sendo surpreendidas, em outras buscando, e quase desejando que os acasos aconteçam como provocação e quebra de nossa própria lógica do que pode ou não ser visto em um evento ao vivo como este em que o conteúdo é importante. A inteligência artificial por trás do dispositivo chama para si o protagonismo da performance e oferece ao público, que de longe acompanha ao vivo, corpos pixelados, borrados, espectros de corpos, corpo-texto, corpo-avatar. Partes do corpo transformadas em quadrados e unidades de cores opacas. Véus virtuais que cobrem em translúcido o que antes era a estrutura identificável de dois corpos femininos. A outra mulher que divide a tela com a primeira divide também a flexibilidade de parâmetros nessa performance que partia da pauta de uma conversa com ausência da oralidade. Audível é o som do ambiente, o som do vento, da respiração, do vizinho pronunciando qualquer coisa ininteligível, ou do "parabéns pra você" cantado pela família que fazia uma festinha de aniversário em uma casa ali perto.

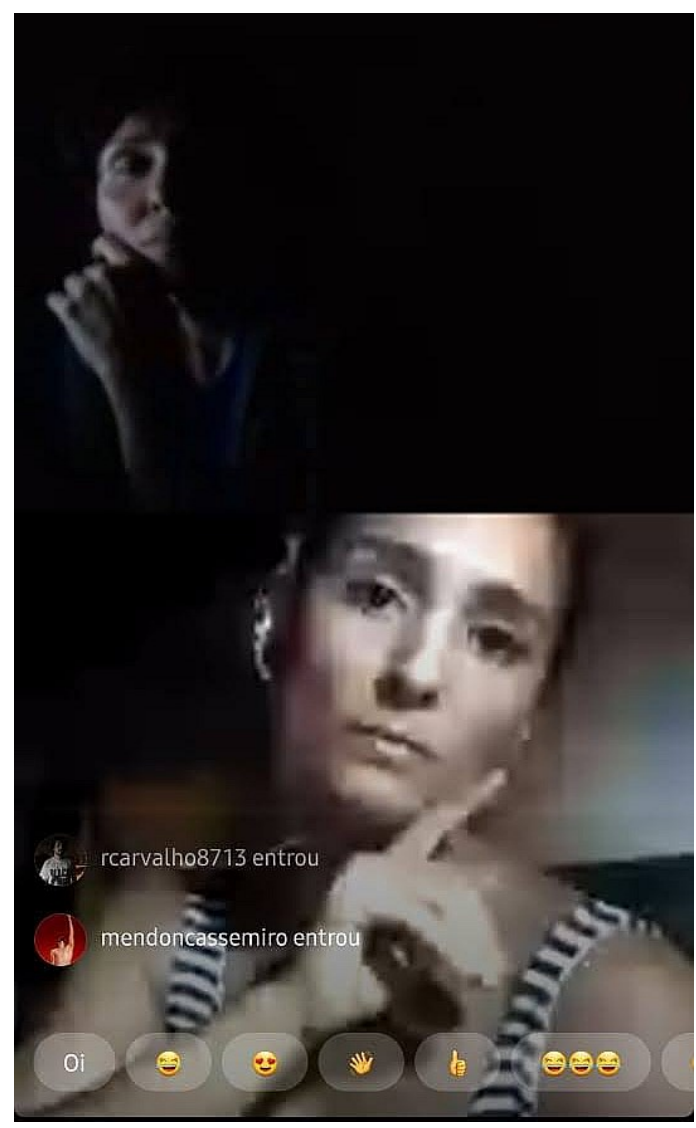

Figura 2: enviado por Eleonora Gabriel Performance em Pauta- Ação 1

Para divulgar o trabalho na própria rede social, uma das estratégias para subverter a expectativa do público foi deixar implícito que esta seria uma live sem conteúdo oral, tentando provocar em quem

3. IP-Internet Protocol : número formado por 32 bits, divididos em 3 octetos, dado a cada dispositivo para o mesmo se comunicar em uma rede. Uma espécie de identidade digital.

R. Inter. Interdisc. Art\&Sensorium, Curitiba, v.7, n.2, p. 181 - 192 Jul.- Dez. 2020 
entrasse no evento um deslocamento e incômodo sobre os códigos pré- estabelecidos do que esperar de uma live, ou melhor, sobre o que definiram que devemos esperar ao entrarmos em uma live. Uma contraditória rigidez de um espaço tão volátil. Para quem entrava nessa "live ratoeira" o que era visto provavelmente não era o esperado, pois ali não havia a emissão de palavras, sílaba por sílaba, formando frases e dando sentido a um possível tema sobre aspectos da performance. Quem entrava não encontrava a mecânica habitual de entrevista ou compartilhamento de conteúdo que poderiam ser úteis de imediato para a assistência.

Quem entrava nessa live via duas mulheres de frente para a tela em silêncio, realizando gestos quase imperceptíveis. Nenhum fonema. Quem entrava poderia também experimentar uma espécie de frustração com base nessa projeção comum do que é uma conversa, antes mesmo do que é uma live. Pra quem se abre, se dispõe e passa por esta frustração, permanecendo no evento

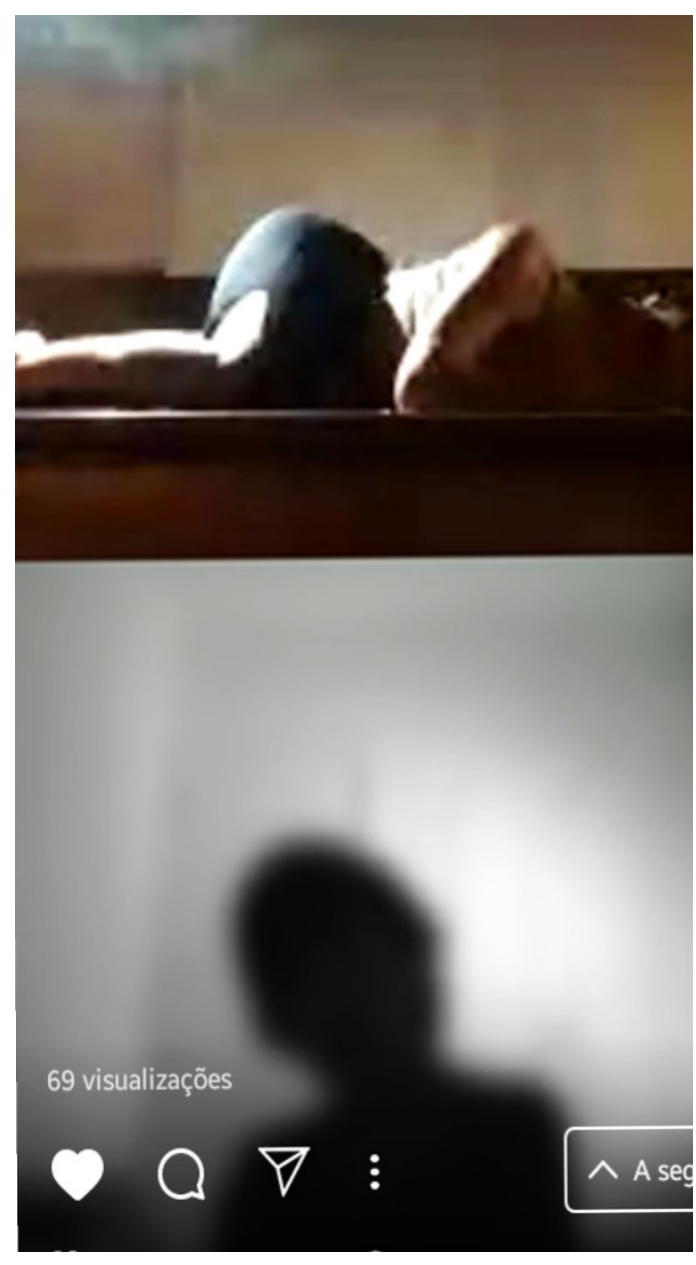

Figura 3: Performance em Pauta - Ação 2

como espectador, começa a soltar-se no espaço desfrutando dessa liberdade de experimentar outras sensações neste lugar-não-lugar. Uma experimentação de outras configurações e possibilidades do que pode ser um diálogo, o que pode ser conteúdo e o que pode ser tempo, como, por exemplo, 1/2 visor com um braço e o outro $1 / 2$ com um corpo deitado.

Com o dispositivo instaurando-se aleatoriamente como mediador, é possível ver corpos variando entre definição e indefinição, incentivando a imaginação da presença na mente de quem assiste, pela proximidade de áreas em que as cores borradas são dispostas, pela forma e pelos acordos préestabelecidos de que ali há de ter outro corpo para se reconhecer uma live. Os 40 minutos de

4. Como o coreógrafo e bailarino Paulo Marques apelidou a live. 
ausência verbal e as falhas de conexão que se transformam em componentes pixelóricos (pixel + pictórico) da imagem do corpo evocam um tempo outro que difere bruscamente ao que estamos habituados na dinâmica de trânsito pelos espaços virtuais. O tempo acelerado das conexões que estabelecemos via internet dá lugar ao tempo do acontecimento da performance, o tempo que pontua o instante (BACHELARD, 2010) diferenciado do tempo que corre incessantemente como o fluxo do rio. Este tempo da ação inesperada suspende o fluxo. O que nos leva a pensar que o tempo é a ação em si mesmo. Onde determinadas ações originam outros tempos, distintas temporalidades em uma cronologia elástica. Desta forma, se tempo é ação, ele também pode ser pensado pela ausência da ação de falar que é a considerada validadora do acontecimento, nesse caso a live. Será então que podemos considerar como uma live o que propusemos? Se pensarmos sob o viés do corpo, do gesto e dos canais plurais de comunicação sensorial para estabelecer um diálogo criando uma fissura no sistema de captura, nossa resposta é absolutamente afirmativa.

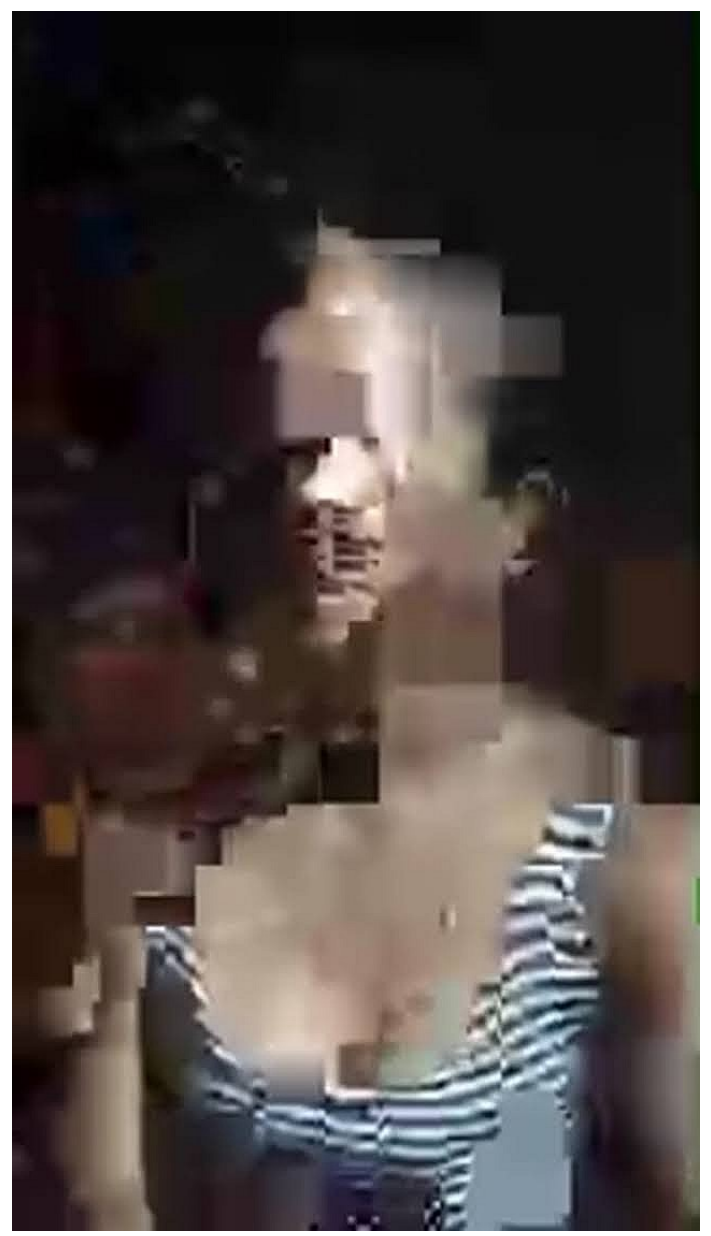

Figura 4: Performance em Pauta - Ação 1

Pensar nesta desconstrução e reconstrução do que se considera diálogo ou fala observando gradativamente a reconfiguração de comportamento dos corpos de espectadores dos trabalhos pode nos levar à ideia de corpomídia cunhado por Helena Katz e Christine Greiner (2005). Nesta proposta há um intermitente trânsito de informações entre o que fica no corpo, modificando-o e o que ele devolve ao ambiente, reconfigurando-o através da comunicação. A mídia à qual a teoria corpomídia se refere diz respeito ao processo evolutivo de selecionar e trocar com o ambiente constituindo espaços, formando mundos e atuando como agente da percepção do corpo como mundo e não como receptáculo. Por exemplo: o "mute" de voz induzido por nós desde o início vai ganhando adesão de quem assiste, diminuindo a constância de comentários escritos pelo público e despertando o silêncio do outro lado também. Reconfigurando ações e, por consequência, reconfigurando corpos. Relevante ressaltar que não defendemos o silêncio como meio único para uma atenção plena, nem mesmo a existência absoluta de um silêncio. Aqui adotamos o silêncio 
apenas como não projeção de voz. Pois, fala é gesto, palavra é gesto, este texto é gesto, mas especificamente nesta pesquisa o intuito é investigar outros meios de diálogo estritamente não verbais em um espaço criado para a verborragia excessiva. Durante o "Performance em Pauta" o silêncio para o outro é pensado como um diálogo interno de auto percepção corporal e de suas possibilidades de comunicação, silêncio esse potencializado pela inconstância de nitidez da imagem, pelos momentos de fragmentação e apagamento dos corpos em meio à transmissão. Este emudecimento e a ausência da certeza de uma imagem fixa, clara e nítida, somados às inúmeras quedas de conexão da rede, cria uma sensação de inadequação ao meio de quem assiste como um possível incômodo, ou uma agonia, como alguns participantes relataram terem sentido. Seria essa impressão de impossibilidade de comunicação presencial nesse momento de pandemia que causa essa aflição? Ou uma fricção de uma anestesia comportamental pré-pandêmica imposta pelo sistema que também nos coloca em posição autômata na virtualidade de nossos feeds, meetings, calls e lives?

A fricção se dá quando rompemos, ou minimamente borramos os limites das linguagens como, por exemplo, nossa proposta de transverter em diálogo de imagens um espaço pensado para um conteúdo de fala, repensando também conceitos como conteúdo e diálogo especificamente para este ambiente.

\section{Entrar e sair, entrar para sair}

O dispositivo em si mesmo é a rede que se estabelece entre os elementos (instituições, leis, discursos, linguísticos e não linguísticos, posições filosóficas (...) Qualquer coisa que tenha de algum modo a capacidade de capturar, orientar, determinar, interceptar, modelar, controlar e assegurar os gestos, as condutas as opiniões e os discursos dos seres viventes. (AGAMBEN, 2009:13)

Tomando a definição acima para dispositivo, podemos dizer que estaríamos presos a um comportamento padronizado e pré-definido, modulador e regulador de nosso 'estar' virtual conduzindo-nos a uma obediência da velocidade, servindo, assim, ao mercado da rede social para o qual voltamos nossa lupa de ação. Nos encontramos capturados no subdispositivo live, adotando aqui o prefixo sub compreendendo a live como um recurso de um dispositivo maior: o aplicativo Instagram. Este subdispositivo que torna artistas, principalmente os que têm o corpo como ponto de partida de suas pesquisas e investigações, reféns de um determinado modo de operar seus processos de criação e atuação no meio, gerando impossibilidades de expansão de seus trabalhos bem como forçando um impedimento ontológico. Desta forma, nesta lógica de mercado que tenta anestesiar os fazeres que não atendem diretamente seus interesses, é possível observar as condutas restauradas conceituadas por Richard Schechner (2006). Para o autor, performances são feitas de porções de comportamentos restaurados, ações executadas pelo menos duas vezes criando hábitos, rituais e rotinas. Todos estes hábitos e rotinas seriam comportamentos restaurados, pois são repetidamente vivenciados.

Estaríamos todos em estado de performance ao entrarmos em uma live ou sempre que acessamos nossos perfis das redes? Dentro deste raciocínio talvez possamos dizer que sim. Poderíamos ainda dizer, sob o ponto de vista de Schechner, que possivelmente estaríamos então propondo uma contraperformance em nossas ações do "Performance em Pauta". A partir de um não-fazer o que é esperado, da não repetição de condutas já estabelecidas nesse meio, não nos deixamos capturar pelo subdispositivo e convidamos o espectador para romper com seu automatismo neste espaço, abrindo portas para pensarmos juntos nosso próprio agir no e com o espaço. Espaço esse que se dispõe em diversas camadas que dialogam entre si. Espaço de quem vê a performance, espaço de cada uma das duas artistas em suas casas, e da própria rede de internet que estabelece uma interseção entre esses espaços numa simbiose, mesmo que temporária, entre fisicalidade e virtualidade reforçados pela 
afecção gerada com o trabalho. Este convite de fissura no sistema estabelece outras relações com o meio e atualiza nosso corpomídia em novos parâmetros. A partir da imagem gerada no enquadramento incomum da tela surge um corpo deformado, por vezes desestruturado por meio de pixels que confundem a estrutura que conhecemos como carne, ossos e fluidos. Nossos corpos, mulheres autoras desse texto, passam a existir também em outras camadas através do espectro que chega aos olhos. Ao abrirmos nossas câmeras para um não fazer fazendo, já que estamos em nossas casas tocando em objetos, lendo livros, sentindo texturas, explorando o espaço, deixando o tempo ser ação conversando entre si e com o próprio dispositivo, mesmo quando esse sublima a visualidade de uma delas, propondo uma atenção a outras sensorialidades que extravazam o visual. Uma qualidade de presença e uma disponibilidade para a coautoria surgem combinadas com a casualidade e a curiosidade, e com estes dois aspectos importantes de nossa investigação emergem outras reflexões.

\section{Presenças desdobradas e quedas}

A questão da presença em trabalhos artísticos sempre se mostrou como fundamental nos estudos sobre diversas áreas, como nas artes cênicas e nas artes visuais, com atenção maior na performance pela própria relação que se estabelece para que esta ocorra: o instante que demanda a presença. A presença como arquivo, a presença pela ausência, os estados de presença, a presentificação do corpo como elemento determinante na arte da performance. Artistas dedicam toda uma vida à lapidação de um estado de presença considerando a mesma como um bem tátil, e fixo a ser assimilado apenas dentro do encontro físico dos corpos. No momento atual esta questão ganha ainda mais protagonismo em especial nas artes que envolvem o corpo. Como estar presente estando ausente? Como estabelecer relações sensoriais tendo a máquina como mediadora? Os campos artísticos vêm debatendo incansavelmente sobre o quanto estar presente ou ausente implica na defesa da existência do próprio campo ou contribui para seu apagamento. Imprescindível compreender neste momento a necessidade de um fazer específico que contemple esta lógica digital. $\mathrm{O}$ fazer físico material jamais será substituído pelo fazer digital e vice-versa. Pensar em adaptações e substituições só aumenta o desgaste e a frustração pode nos paralisar negativamente. Para lógicas específicas e distintas de fazeres relacionais emergem outras tantas gamas de presenças possíveis a serem experimentadas, excedendo os sentidos para esta palavra.

Sob esta ótica nossa investigação contra-performática, se assim a podemos chamar, propõe a possibilidade de gerar um estado de presença outro a partir desta relação conjuntiva com o digital, entendendo presença como campo de força e energia resultante da relação de corpos (FERRACINI; FEITOSA, 2017, 114). Portanto pensar a presença sobre o viés da qualidade das relações para além da materialidade ou fisicalidade pode estabelecer uma porosidade no termo ajudando a compreender os desdobramentos possíveis de nosso fazer artístico e, por sua vez, de nosso estado de arte, ou ainda, de nossos estados de presença, plural no sentido de múltiplo. Pode nos levar refletir sobre uma noção de corpo para além da matéria. Podemos pensar o meio digital como um fazer potencializador e expansivo de corpos, uma presença radical como efeito de uma zona de forças em relação, ampliação do poder de afetar e ser afetado (ibid.,p.117).

Dentro das ações realizadas no "Performance em Pauta" a experiência de coautoria se mostrou constante. Não apenas nas relações mais óbvias entre nós duas, artistas proponentes, mas com o espectador e com a própria rede. Os atos falhos de quedas de conexão se colocaram como cocriadores na medida que impossibilitavam de fato as incansáveis tentativas de reconexão para seguir com o programado. Quando cedemos a estas quedas e absorvemos o tempo e a ação da rede no trabalho, passamos a operar em estado de escuta e em trio: Fernanda, Mery e a rede. Essa atenção nos levou a muitos caminhos, que somente a coautoria da rede pode nos dar, e que, inclusive, ficaram elencados para as futuras ações. As imagens travando em frames de uma de nós repetidas vezes e as quedas insistentes impedindo que a outra entrasse na live acabaram nos levando 
a uma reorganização corporal e criativa facilitada pelo estado de atenção aos sinais que surgiam pelas interferências. A opção consistia em abrir essas portas oferecidas por essa coautoria e explorar uma capacidade de lidar com o erro e convertê-lo em algo desconhecido, ou fechar a porta de possibilidades e manter o que antes havia sido combinado. A casualidade do erro foi incorporada e começamos a explorar nossa presença radical nos deslocando para o espaço dos comentários, em forma de texto escrito em que uma de nós observava e, de maneira intuitiva, gesticulava uma resposta por escrito. Estes comentários, por sua vez, subvertiam também o espaço do espectador, provocando outras relações, potencializando-as.

Uma vez aberta esta porta da coautoria e do borramento de fronteiras entre autoras, espectadores e rede, outras tantas obras e propostas performativas ou não-performáticas acabaram surgindo.“ É exatamente no acesso aos meios de criação e na mistura, tanto de referências como de "maneiras de criar' que surgem não só novos autores, mas também uma nova definição de obra." (CERBINO; MENDONÇA, 2001, p.355)

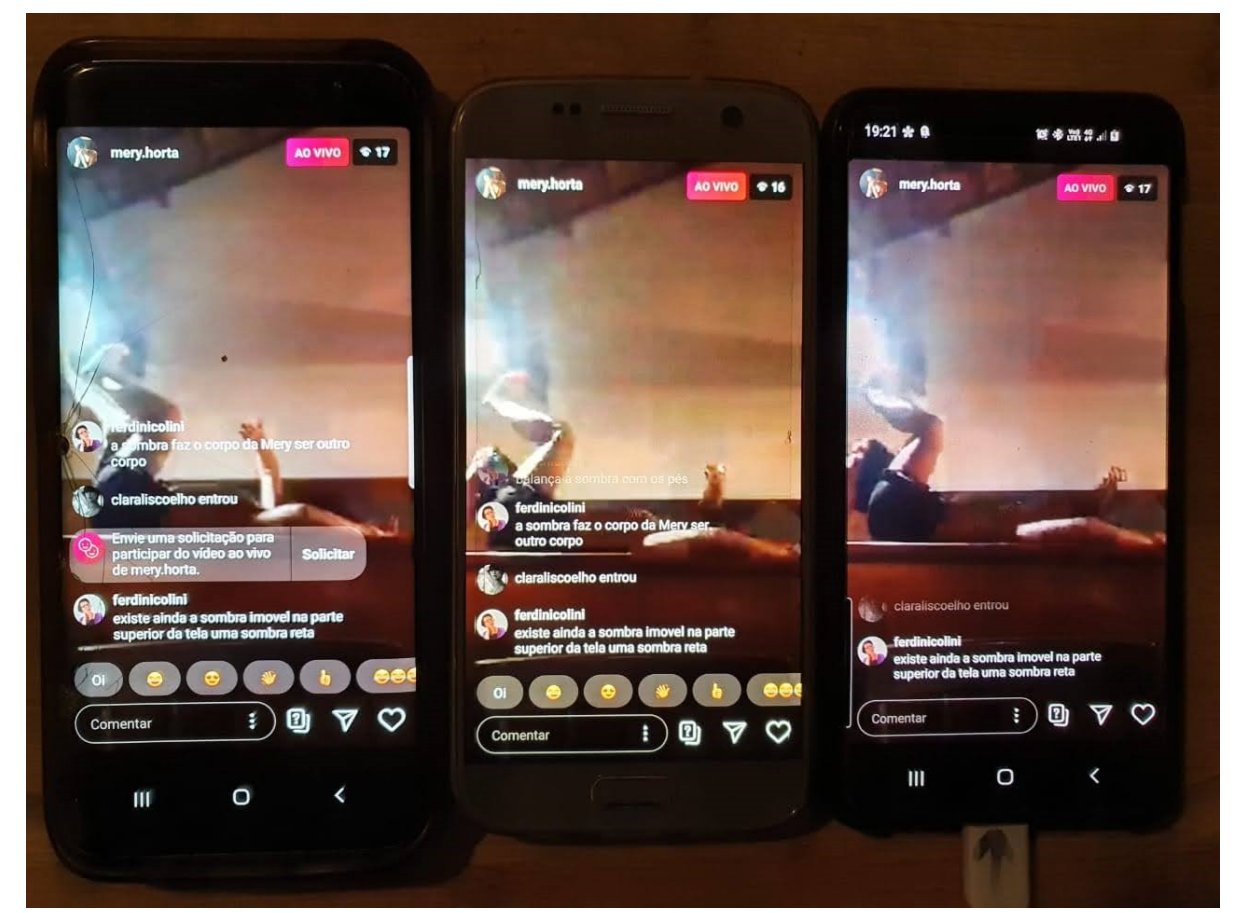

Figura 5: Registro enviado por Yasmin Coelho - Performance em Pauta - Ação2

A experiência com o "Performance em Pauta" reafirmou novas definições de nossa própria obra, como é o caso da imagem acima. Esta imagem é um frame de um pequeno vídeo-registro de um momento de coautoria. Ela nos foi enviada após o término da segunda ação realizada. A artista Yasmin Coelho de Andrade assistia a live e estava tendo dificuldades de conexão com a rede de dados do seu celular e, para conferir, solicitou o aparelho celular de outras pessoas que estavam juntas na mesma casa assistindo ao trabalho para comparar as imagens. Ao unir os celulares percebeu que os três aparelhos juntos, apesar de estarem no mesmo evento, mostravam imagens em momentos diferentes. Cada rede de cada aparelho intervindo de uma maneira diferente e provocando relações distintas. Corpos desdobrados e, por sua vez, outros estados de presença. Imediatamente, no ato da percepção sensível, a espectadora, que nesse momento assume deliberadamente a coautoria do trabalho, registra essa intervenção em formato de vídeo, de modo que a imagem gerada não é uma colagem ou montagem de frames, mas sim um frame de três versões de um mesmo trabalho somadas à versão de seu próprio registro como uma quarta imagem, ou ainda quatro outras obras. 
Da mesma forma que Yasmin assumiu um lugar de proposição em meio ao trabalho, outras pessoas que assistiram nos relataram posteriormente que entravam em contato com algum amigo que também assistia e enviava prints da tela para comparar as imagens, pensando estar com problemas na própria conexão. A falha oferecida pelo sistema e incorporada por nós no momento da live gerava imagens que tendiam a desestabilizar quem assistia. Passado um momento inicial de estranhamento, as pessoas tendiam a desfrutar de um tempo dilatado provido em parte pelo silêncio e em parte por essa incorporação do erro, tempo esse esgarçado que reforça a relação com o instante, conforme relatado por várias pessoas do público, quebrando a dinâmica frenética que normalmente é experienciada no uso da internet. Receber estes relatos e os vídeos que se apresentam como formas de afecção nos motivou ainda mais a seguir com a investigação que a partir de então se colocará em um outro ponto de escuta aberta e disponível, confirmando que as especificidades de atuar na arte digital expandem o campo e a compreensão sobre nós mesmos, sobre o meio e sobre a arte em si, algo que pode, em um mundo pós-pandêmico, colaborar para uma visão mais expandida e sensível.

\section{Considerações Finais}

A restrição da circulação dos corpos humanos por espaços físicos advinda da pandemia de Covid-19 instigou uma circulação maior pelo meio virtual. A necessidade da circulação dos nossos corpos projetados na virtualidade em busca das mais variadas coisas ultrapassou relações de trabalho e pesquisa, sendo parte importante na própria manutenção do afeto entre as pessoas. A criação de formas outras de estar diante da presença humana e a manutenção de outras já existentes através das ferramentas digitais se mostraram como um caminho viável para que diversas atividades se mantivessem em período de isolamento social e outras fossem criadas. Nesse bojo de um cosmos temporal pandêmico vimos surgir o boom das lives como uma forma de lidar com um possível tempo ocioso, divulgar trabalhos e conteúdos, ou simplesmente, diminuir a sensação de solidão. A presença do corpo se transverte na presença da imagem mediada por dispositivos digitais, com isso as transmissões "ao vivo" ganham a camada digna de um fetiche ao comercializar a intimidade como produto, se afirmando como mais um dispositivo de captura social com seus protocolos. Em vias confluentes e contraditórias, muitos artistas mantém suas atividades e passam a abranger a reflexão sobre esses modos de se relacionar, nada novos, porém com outras perspectivas derivadas da contemporaneidade de uma sociedade em pandemia.

Nesse contexto de trânsito pelo meio virtual as autoras desse texto se conheceram e iniciaram encontros de pesquisa e criação que resultaram em duas edições da live "Performance em Pauta". Um trabalho que parte de reflexões sobre modos de comportamento e formatações de imagem proveniente das lives, espaço com predominante oralidade. Um trabalho que não se restringe na busca por uma definição ou exaltação do uso de tecnologia, "Performance em Pauta" consiste, antes de mais nada, de um conversa, um diálogo sem emissão audível de palavras, uma relação afetiva entre corpos que não compartilham o mesmo espaço físico, e sim, a presença em diferentes camadas conjuntivas facilitada pelo meio virtual. Um trabalho que constrói com autonomia estados radicais de presença. Trabalhando a partir de brechas do que escapa como normalidade, os corpos das duas performers se deparam com falhas e erros de conexão e, talvez, dos próprios dispositivos, que são incorporados ao trabalho como mais uma ferramenta para uso. Neste sentido, o erro pode ser mais um dispositivo que assumimos dessa contra-performance. Os artistas exploram as contradições dos meios, inclusive do tecnológico (PRADO, 2003), e nesse caso, o conteúdo tão caro às lives se torna o próprio ato de realizá-la. O meio como conteúdo.

A conversa estabelecida na ausência de som concentra a atenção de quem acompanha a ação na imagem dos corpos. Os componentes pixelóricos evocam um tempo dilatado e divergente do tempo usual dos dispositivos digitais. Esse silêncio proposto é potencializado pela coautoria da rede que fragmenta e apaga os corpos, criando unidades de cor e formas indefinidas. A interferência tensiona 
a expressão das individualidades, comum nas redes sociais, do mesmo modo que convida à coautoria do público participante. Assim, a presença dos corpos transvertida em imagem se dá na relação entre energias físicas e virtuais pela sobreposição de diversas camadas de subjetividade projetadas tanto pelo meio quanto pelos corpos. Uma proposta que fricciona tempo, espaço, corpo, relações e autoconhecimento.

\section{REFERÊNCIAS}

AGAMBEN, G. O que é o contemporâneo? E outros ensaios. Chapecó: Argos, 2009.

BACHELARD, G. A intuição do instante. Campinas, SP: Verus Editora, 2010.

CERBINO, B; MENDONÇA, L. Considerações sobre as relações entre autoria, dança, cinema e videodança. Liinc em Revista,v.7,n.2. DOI: 10.18617/liinc.v7i2.435 Acesso em: 19 Set 2020.

DOMINGUES, D. A arte no século XXI: a humanização das tecnologias. Org. São Paulo: Fundação Editora da UNESP, 1997.

FEITOSA, C.; FERRACINI, R. A questão da presença na filosofia e nas artes cênicas. Ouvirouver, Uberlândia, v.13, n.1, p.106-118, Jan-Jun 2017.

GREINER, C. O corpo: pistas para estudos indisciplinares. São Paulo: Annablume, 2005.

PRADO, G. Arte Telemática: dos intercâmbios pontuais aos ambientes virtuais multiusuário. São Paulo: Itaú Cultural, 2003.

SCHECHNER, R. O que é performance? In: SCHECHNER, R. Performance studies: an introduction. $2^{\mathrm{a}}$ edição. New York \& London: Routledge, 2006. Páginas 28-51. 